\title{
A New Approach Using Aromatic-Solvent-Induced Shifts in NMR Spectroscopy to Analyze $\beta$-Lactams with Various Substitution Patterns
}

\author{
Leticia Chavelas-Hernández \\ Jonathan R. Valdéz-Camacho \\ Luis G. Hernández-Vázquez \\ Blanca E. Dominguez-Mendoza \\ María G. Vasquez-Ríos \\ Jaime Escalante* (D) \\ Centro de Investigaciones Químicas and Laboratorio Nacional \\ de Estructura de Macromoléculas, Universidad Autónoma del \\ Estado de Morelos, Av. Universidad No. 1001, Col. Chamilpa, \\ C.P. 62209, Cuernavaca, Mor., México \\ jaime@uaem.mx
}

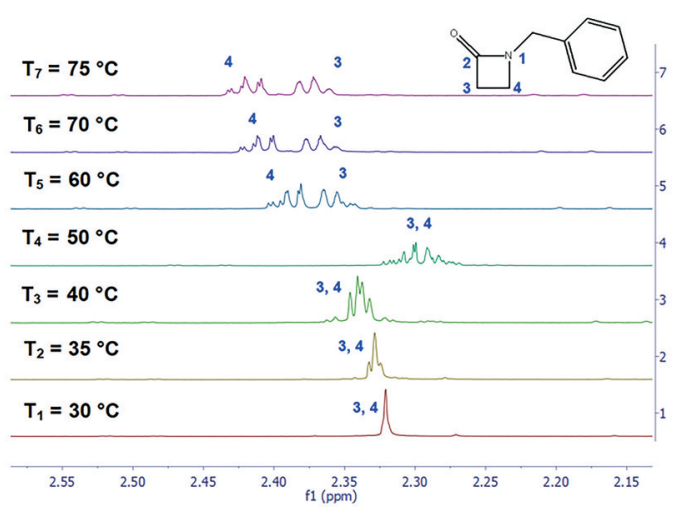

the positive end of the dipole, whereas at the peripheral edge of the molecule will be oriented toward to the negative part of the dipole. ${ }^{9}$ Other explanations have also been proposed for the origin of the ASIS effect, such as the induced quadrupole-quadrupole interaction model, ${ }^{6}$ the hydrogen-bond interaction model, ${ }^{10}$ a solvent-solute model of $1: 1$ complexes, and the formation of time-averaged clusters. ${ }^{11}$

The anisotropy of benzene can help to disclose solutesolvent interactions that might not be detected without it. For example, ASIS has been used to differentiate axial and equatorial hydrogen atoms or methyl substituents alpha to carbonyl groups. In cyclohexanone, the ${ }^{1} \mathrm{H}$ NMR signal for an axial 2-methyl group is shifted $0.2-0.3 \mathrm{ppm}$ upfield in benzene compared with that in tetrachloromethane, whereas the signal for an equatorial 2-methyl group is shifted $0.005-0.1$ ppm downfield. ${ }^{3}$ This has been used to define the configuration at the 2-position and to measure the conformational equilibrium in 2-methylcyclohexanone.

The carbonyl-plane rule permits the location of hydrogen atoms relative to a keto group (Figure 1). ${ }^{1-14}$ If we imagine a plane perpendicular to the $\mathrm{C}-\mathrm{CO}-\mathrm{C}$ plane that passes through the $\mathrm{sp}^{2}$ carbon, the value of $\Delta \delta$ (ASIS) is positive for hydrogen atoms lying in front of the perpendicular plane and negative for those lying behind it. As can be seen

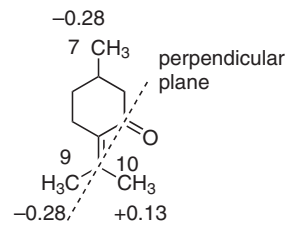

$\Delta \delta\left({ }^{1} \mathrm{H}\right.$-ASIS $)$ of pulegone in ppm

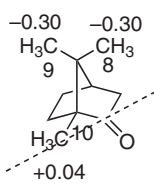

$\Delta \delta\left({ }^{1} \mathrm{H}-\mathrm{ASIS}\right)$ of camphor in ppm

Figure 1 Examples of the carbonyl-plane rule 
in Figure 1 , the $\Delta \delta$ (ASIS) values for pulegone are positive for the methyl group in front of the plane perpendicular to the $\mathrm{C}-\mathrm{CO}-\mathrm{C}$ plane and negative for methyl groups lying behind this plane. A similar effect is observed for camphor. ${ }^{12}$

When we synthesized a series of cyclic $\beta$-dipeptides and $\beta$-lactams with various substitution patterns and examined their ${ }^{1} \mathrm{H}$ NMR spectra, we obtained important results on applying the ASIS methodology. We observed that ${ }^{1} \mathrm{H}$ chemical shifts for aliphatic protons in these compounds exhibited outstanding differences in multiplicity as well as changes in chemical shifts when we used benzene- $d_{6}\left(C_{6} D_{6}\right)$ and chloroform- $d_{1}\left(\mathrm{CDCl}_{3}\right)$ as solvents. ${ }^{15}$ On the basis of these results, we decided to study the ASIS effect in $\beta$-lactams with specific substitution patterns.

For this study the samples were prepared at an equal concentration of $47 \mathrm{mM}$ and $\mathrm{w}^{1 / 2}=0.5$ in $\mathrm{CDCl}_{3}$ and $\mathrm{C}_{6} \mathrm{D}_{6}$ as solvents. The first $\beta$-lactam in the working group for which an ASIS effect was observed was $\beta$-lactam 1. In the ${ }^{1} \mathrm{H}$ NMR spectrum recorded in chloroform- $d_{1}$ as the solvent, we observed a triplet shifted to $\delta=3.02 \mathrm{ppm}$, corresponding to the $\mathrm{H}-3$ proton. At $\delta=3.31 \mathrm{ppm}$ there was a second triplet corresponding to the $\mathrm{H}-4$ proton. On switching to $\mathrm{C}_{6} \mathrm{D}_{6}$ as solvent, we expected a change in the chemical shifts of the signals, but surprisingly we observed a single signal at $\delta=$ $2.39 \mathrm{ppm}$ corresponding to the $\mathrm{H}-3$ and $\mathrm{H}-4$ protons (Table 1 ). To establish the effect of a substituent $R^{1}$ on the $\mathrm{N}$ atom, we synthesized the $\beta$-lactam derivatives $2-6 .{ }^{16}$ For compound 2, we introduced a methyl group, whereas for derivatives 3-6, anisotropy was introduced to determine its effect in benzene as a solvent.

On comparing chemical-shift changes in compounds 1$\mathbf{6}$, we can see that the methyl derivative $\mathbf{2}$ shows the greatest value for the $\mathrm{H}-4$ chemical shift, and its calculated ASIS effect shows a value of a $\Delta \delta 4=-1.05$, meaning that the anisotropy of benzene shields the protons causing upfield changes. On the other hand, the introduction of anisotropy at the nitrogen atom for lactams 3-6 showed that the $\mathrm{H}-3$ protons are less affected by the benzene ring, whereas the $\mathrm{H}-4$ protons exhibited the same chemical shift change in the aromatic medium, so that the $\mathrm{N}-\mathrm{H}$ and $\mathrm{N}-\mathrm{Ar}$ systems are affected in the same way. As can be seen, the protons $\mathrm{H}-$ 4 are the most affected by a solvent change for the methyl derivative 2 . To confirm this finding, HSQC and HMBC spectra recorded in $\mathrm{CDCl}_{3}$ and $\mathrm{C}_{6} \mathrm{D}_{6}$ were used to confirm the assignment of $\mathrm{H}-3$ and $\mathrm{H}-4$ to their corresponding carbon atoms.

Table $1{ }^{1} \mathrm{H}$ NMR Chemical Shifts and ASIS Analyses for $\beta$-Lactams 1-8 in $\mathrm{CDCl}_{3}$ and $\mathrm{C}_{6} \mathrm{D}_{6}(400 \mathrm{MHz})$

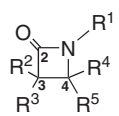

\begin{tabular}{|c|c|c|c|c|}
\hline$\beta$-Lactam & & $\mathrm{CDCl}_{3}$ (multiplicity, $\delta \mathrm{ppm}$ ) & $\mathrm{C}_{6} \mathrm{D}_{6}$ (multiplicity, $\delta \mathrm{ppm}$ ) & $\Delta \delta(A S I S)=\delta_{A S}-\delta_{S}$ \\
\hline 1 & $\mathrm{R}^{1}, \mathrm{R}^{2}, \mathrm{R}^{3}, \mathrm{R}^{4}, \mathrm{R}^{5}=\mathrm{H}$ & $\begin{array}{l}\mathrm{H}-3(\mathrm{t}, 3.02) \\
\mathrm{H}-4(\mathrm{t}, 3.31)\end{array}$ & $\mathrm{H}-3, \mathrm{H}-4$ (s, 2.39) & $\begin{array}{l}\Delta \delta 3=-0.63 \\
\Delta \delta 4=-0.92\end{array}$ \\
\hline 2 & $\begin{array}{l}\mathrm{R}^{1}=\mathrm{CH}_{3} \\
\mathrm{R}^{2}, \mathrm{R}^{3}, \mathrm{R}^{4}, \mathrm{R}^{5}=\mathrm{H}\end{array}$ & $\begin{array}{l}\mathrm{H}-3(\mathrm{t}, 2.95) \\
\mathrm{H}-4(\mathrm{t}, 3.23) \\
\mathrm{CH}_{3}-5(\mathrm{~s}, 2.83)\end{array}$ & $\begin{array}{l}\mathrm{H}-3(\mathrm{t}, 2.31) \\
\mathrm{H}-4(\mathrm{t}, 2.19) \\
\mathrm{CH}_{3}-5(\mathrm{~s}, 2.21)\end{array}$ & $\begin{array}{l}\Delta \delta 3=-0.64 \\
\Delta \delta 4=-1.05 \\
\Delta \delta 5=-0.62\end{array}$ \\
\hline 3 & 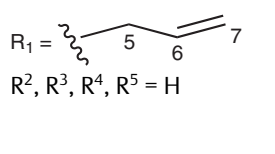 & $\begin{array}{l}\mathrm{H}-3(\mathrm{t}, 2.96) \\
\mathrm{H}-4(\mathrm{t}, 3.23) \\
\mathrm{H}-5(\mathrm{~d}, 3.82) \\
\mathrm{H}-6(\mathrm{~m}, 5.74) \\
\mathrm{H}-7(\mathrm{~m}, 5.25)\end{array}$ & $\begin{array}{l}\mathrm{H}-3, \mathrm{H}-4(\mathrm{~m}, 2.34) \\
\mathrm{H}-5(\mathrm{~d}, 3.39) \\
\mathrm{H}-6(\mathrm{~m}, 5.32) \\
\mathrm{H}-7(\mathrm{~m}, 4.82)\end{array}$ & $\begin{array}{l}\Delta \delta 3=-0.62 \\
\Delta \delta 4=-0.89 \\
\Delta \delta 5=-0.43\end{array}$ \\
\hline 4 & $\begin{array}{l}R^{1}=B n \\
R^{2}, R^{3}, R^{4}, R^{5}=H\end{array}$ & $\begin{array}{l}\mathrm{H}-3(\mathrm{t}, 2.94) \\
\mathrm{H}-4(\mathrm{t}, 3.13) \\
\mathrm{CH}_{2}-5(\mathrm{~s}, 4.37) \\
\mathrm{Ph}(\mathrm{m}, 7.34)\end{array}$ & $\begin{array}{l}\mathrm{H}-3, \mathrm{H}-4(\mathrm{~s}, 2.31) \\
\mathrm{H}-5(\mathrm{~s}, 4.02) \\
\mathrm{Ph}(\mathrm{m}, 7.00)\end{array}$ & $\begin{array}{l}\Delta \delta 3=-0.63 \\
\Delta \delta 4=-0.82 \\
\Delta \delta 5=-0.35\end{array}$ \\
\hline 5 & $\begin{array}{l}\mathrm{R}^{1}=(1 \text {-naphthyl)methyl; } \\
\mathrm{R}^{2}, \mathrm{R}^{3}, \mathrm{R}^{4}, \mathrm{R}^{5}=\mathrm{H}\end{array}$ & $\begin{array}{l}\mathrm{H}-3(\mathrm{t}, 2.86) \\
\mathrm{H}-4(\mathrm{t}, 2.99) \\
\mathrm{CH}_{2}-5(\mathrm{~s}, 4.80) \\
\mathrm{Ar}(\mathrm{m}, 7.37-8.12)\end{array}$ & $\begin{array}{l}\mathrm{H}-3, \mathrm{H}-4(\mathrm{~m}, 2.20) \\
\mathrm{CH}_{2}-5(\mathrm{~s}, 4.43) \\
\operatorname{Ar}(\mathrm{m}, 6.97-8.34)\end{array}$ & $\begin{array}{l}\Delta \delta 3=-0.66 \\
\Delta \delta 4=-0.79 \\
\Delta \delta 5=-0.37\end{array}$ \\
\hline 6 & $\begin{array}{l}R^{1}=(1 \text {-anthryl)methyl; } \\
R^{2}, R^{3}, R^{4}, R^{5}=H\end{array}$ & $\begin{array}{l}\mathrm{H}-3(\mathrm{t}, 2.81) \\
\mathrm{H}-4(\mathrm{t}, 2.88) \\
\mathrm{CH}_{2}-5(\mathrm{~s}, 5.36) \\
\operatorname{Ar}(\mathrm{m}, 7.40-8.60)\end{array}$ & $\begin{array}{l}\mathrm{H}-3, \mathrm{H}-4(\mathrm{~m}, 2.09) \\
\mathrm{CH}_{2}-5(\mathrm{~s}, 4.98) \\
\mathrm{Ar}(\mathrm{m}, 7.11-8.34)\end{array}$ & $\begin{array}{l}\Delta \delta 3=-0.72 \\
\Delta \delta 4=-0.79 \\
\Delta \delta 5=-0.38\end{array}$ \\
\hline 7 & $\begin{array}{l}\mathrm{R}^{1}=\mathrm{H} \\
\mathrm{R}^{2}, \mathrm{R}^{3}, \mathrm{R}^{4}, \mathrm{R}^{5}=\mathrm{CH}_{3}\end{array}$ & $\begin{array}{l}\mathrm{H}-5(\mathrm{~s}, 1.11) \\
\mathrm{H}-6(\mathrm{~s}, 1.22)\end{array}$ & $\begin{array}{l}\mathrm{H}-5(\mathrm{~s}, 1.00) \\
\mathrm{H}-6(\mathrm{br} \mathrm{s}, 0.86)\end{array}$ & $\begin{array}{l}\Delta \delta 5=-0.11 \\
\Delta \delta 6=-0.36\end{array}$ \\
\hline 8 & $\begin{array}{l}R^{1}=\mathrm{Bn} ; \\
R^{2}, R^{3}, R^{4}, R^{5}=C_{3}\end{array}$ & $\begin{array}{l}\mathrm{H}-5(\mathrm{~s}, 1.21) \\
\mathrm{H}-6(\mathrm{~s}, 1.11) \\
\mathrm{CH}_{2}-7(\mathrm{~m}, 4.26) \\
\mathrm{Ph}(\mathrm{m}, 7.13)\end{array}$ & $\begin{array}{l}\mathrm{H}-5(\mathrm{~s}, 1.02) \\
\mathrm{H}-6(\mathrm{~s}, 0.73) \\
\mathrm{CH}_{2}-7(\mathrm{~m}, 4.02) \\
\mathrm{Ph}(\mathrm{m}, 7.10)\end{array}$ & $\begin{array}{l}\Delta \delta 5=-0.19 \\
\Delta \delta 6=-0.38 \\
\Delta \delta 7=-0.24\end{array}$ \\
\hline
\end{tabular}


To obtain a better idea of the ASIS effect observed for compound $\mathbf{2}$, we conducted a titration experiment analyzed by ${ }^{1} \mathrm{H}$ NMR. $\beta$-lactam $2\left(5.0 \times 10^{-5}\right.$ moles $)$ was dissolved in $350 \mu \mathrm{L}$ of $\mathrm{CDCl}_{3}$ and a first spectrum was obtained. When aliquots of $1.13 \times 10^{-3}$ moles of $\mathrm{C}_{6} \mathrm{D}_{6}$ were added up to $6.77 \mathrm{mmol}$, we observed that as the concentration of $\mathrm{C}_{6} \mathrm{D}_{6}$ increased, the signals for $\mathrm{H}-3$ and $\mathrm{H}-4$ approached and then overlapped one another (Figure 2).

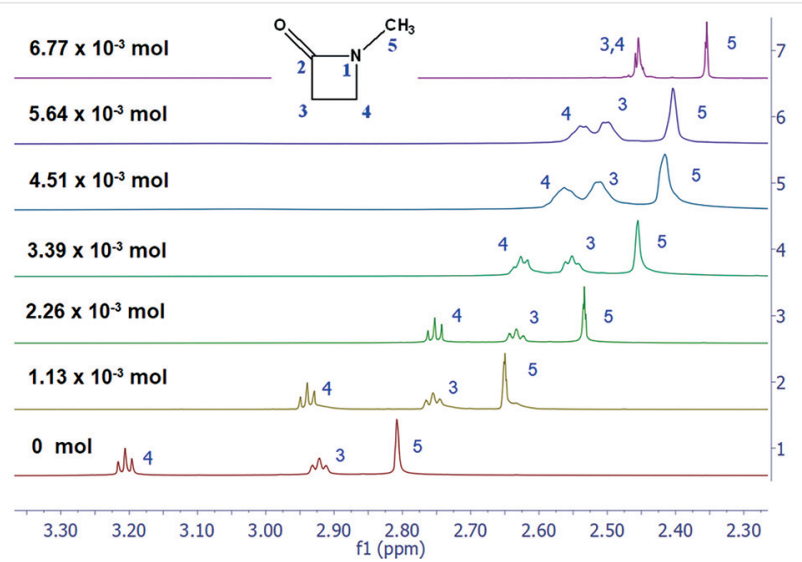

Figure $2{ }^{1} \mathrm{H} \mathrm{NMR}(400 \mathrm{MHz})$ of $\beta$-lactam 2 in $\mathrm{CDCl}_{3}$ containing increasing concentrations of $\mathrm{C}_{6} \mathrm{D}_{6}$

Surprisingly, $\beta$-lactam 4 in $\mathrm{C}_{6} \mathrm{D}_{6}$ at $25^{\circ} \mathrm{C}$ did not show the expected change in its chemical shift; instead, a single signal at $\delta=2.32 \mathrm{ppm}$ corresponding to protons $\mathrm{H}-3$ and $\mathrm{H}-$ 4 was observed. To explain and verify this finding, we performed a variable-temperature experiment (Figure 3). The single signal became split into two multiple signals as the temperature was increased from 30 to $75^{\circ} \mathrm{C}$.

In the case of amides the participation of dipole resonating forms causes the benzene atom to be located near the nitrogen atom and as far as possible from the oxygen

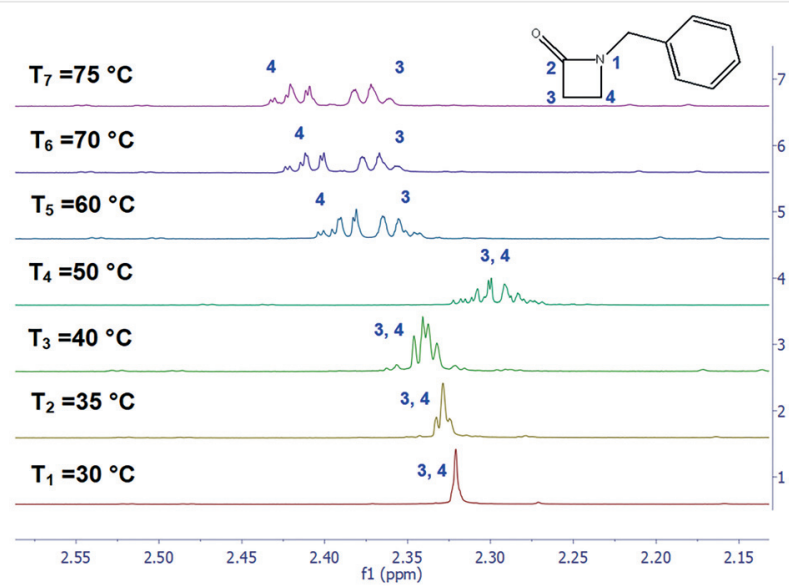

Figure $3{ }^{1} \mathrm{H}$ NMR $(500 \mathrm{MHz})$ variable-temperature experiment for $\beta$ lactam 4 in $\mathrm{C}_{6} \mathrm{D}_{6}$ atom (Figure 4). The same phenomenon might also be observed in $\beta$-lactams, which would explain why the $\mathrm{H}-4$ protons were more affected by a change in the solvent from $\mathrm{CDCl}_{3}$ to $\mathrm{C}_{6} \mathrm{D}_{6}$, causing a greater shift of the signals towards lower frequencies. This was confirmed by introducing allyl and aryl substituents into $\beta$-lactams 3-6. In these cases, the signal from $\mathrm{H}-3$ was less affected by stacking of the benzene ring with the allyl or aryl groups.

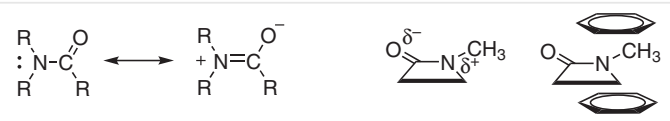

Figure 4 Amide resonance forms and possible interactions between a $\beta$-lactam molecule and two benzene molecules

To develop a structural analysis of $\beta$-lactams, we performed theoretical calculations by using density functional theory (DFT). The optimized geometry of the $\beta$-lactam 2 was placed in the middle of a stacking displaced (SD) model that represents the hypothetical structural conditions that explain the ASIS effect in $\beta$-lactams by considering a distance slightly greater than the van der Waals radius between 2 and the benzene rings (Figure 5).
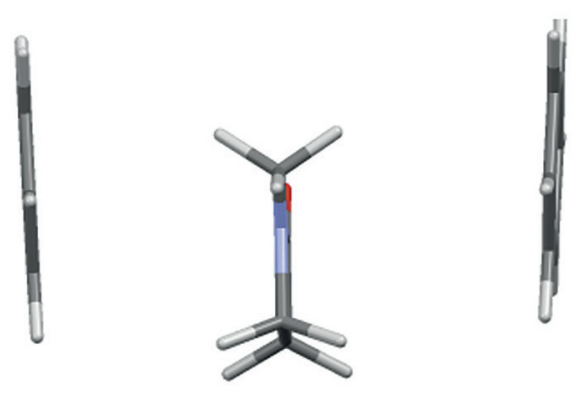

\section{SD}

Figure 5 Stacking displaced adduct of $\beta$-lactam $\mathbf{2}$ with two benzene molecules

First, the shielding effect $\left[\Delta_{\delta \delta}\right.$ (ASIS)] of the aromatic rings over $\mathrm{H}-3$ and $\mathrm{H}-4$ was evaluated. The best model is that which approximates the value of $\Delta_{\delta \delta}$ (ASIS) nearest to zero. The analysis confirmed that the SD perspective reproduced the experimental data (SD in Table 2).

To examine whether the SD configuration corresponds to the more stable arrangement for the trimer, a geometry optimization at the same level of theory were carried out. By analyzing the optimized geometries of the adduct (OA in Table 2), it was demonstrated that the SD perspective does not correspond to a minimum and that the stacking aggregation needs to be reconsidered. By comparing the results obtained by using two different functionals, it is possible to see that the $\omega$-B97XD functional gives a better description 
Table 2 Theoretical Chemical Shifts and Analysis of the ASIS Effect for the $\beta$-Lactam 2

\begin{tabular}{|c|c|c|}
\hline \multirow[t]{2}{*}{ Functional } & \multicolumn{2}{|c|}{$\Delta_{\delta \delta}(\mathrm{ASIS})=\Delta_{\delta \exp }(\mathrm{ASIS})-\Delta_{\delta \text { theo }}(\mathrm{ASIS})$} \\
\hline & $\begin{array}{l}\text { Stacking displaced } \\
\text { (SD) }\end{array}$ & $\begin{array}{l}\text { Optimized geometry of the adduct } \\
\text { (OA) }\end{array}$ \\
\hline B3LYP & $\begin{array}{l}\Delta_{\delta \delta} 3=0.50 \\
\Delta_{\delta \delta} 4=-0.32 \\
\Delta_{\delta \delta} 5=-0.01\end{array}$ & $\begin{array}{l}\Delta_{\delta \delta} 4=-1.69 \\
\Delta_{\delta \delta} 3=-0.75 \\
\Delta_{\delta \delta} 5=-0.67\end{array}$ \\
\hline$\omega B 97 X D$ & $\begin{array}{l}\Delta_{\delta \delta} 3=0.61 \\
\Delta_{\delta \delta} 4=-0.13 \\
\Delta_{\delta \delta} 5=0.05\end{array}$ & $\begin{array}{l}\Delta_{\delta \delta} 4=0.82 \\
\Delta_{\delta \delta} 3=-0.15 \\
\Delta_{\delta \delta} 5=-0.32\end{array}$ \\
\hline
\end{tabular}

of the change in chemical shifts (Table 2) than does the B3LYP functional. First, the optimized geometry of the trimer obtained by using the $\omega$-B97XD functional predicts a stacking displaced configuration between the $\beta$-lactam 2 and one molecule of benzene (Figure 6a), whereas the optimization using the B3LYP functional suggest that two molecules of benzene are far from the $\mathbf{2}$ molecule (Figure $6 \mathrm{~b}$ ). Also, it is assumed that this enhancement arises from a better description of the dispersion interactions from the $\omega$ B97XD functional.

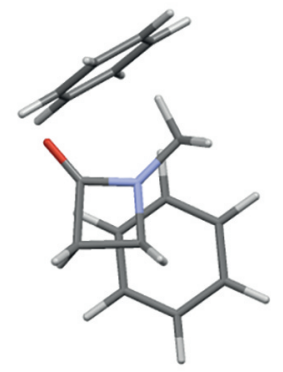

a

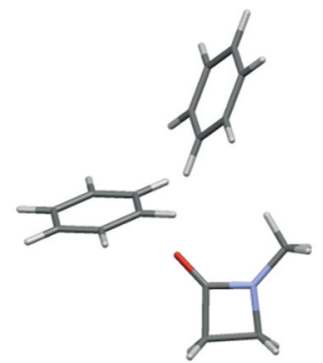

b
Figure 6 Optimized geometries of $\beta$-lactam 2 with two molecules of benzene

Obviously, this study supported the idea of stacking protection from benzene rings to the $\beta$-lactam ring, but a more rigorously approximation is necessary to permit the evaluation of the bulk effect of the solvent. A likely $\mathrm{CH}-\pi$ interaction has been suggested in comparing the theoretical parameters (distances) reported for this kind of interaction, which are in the range 3.2-3.8 $\AA .{ }^{17,18}$ In the present work, we found a range of distances between 3.18 to 4.8 , which confirmed the presence of a weak $\mathrm{CH}-\pi$ interaction.

We then performed a ${ }^{15} \mathrm{~N}$ HSQC experiment to examine the ASIS effect for the amide moiety in compound $\mathbf{1}$. The solvent aromatic ring exhibited a deshielded effect over the ${ }^{15} \mathrm{~N}$ and ${ }^{1} \mathrm{H}$ chemical shifts, confirming the presence of the interaction shown in Figure 4. This means that the lactam protons are close to the shielding effect of the benzene ring, whereas $\mathrm{NH}$ is deshielded (Figure 7).

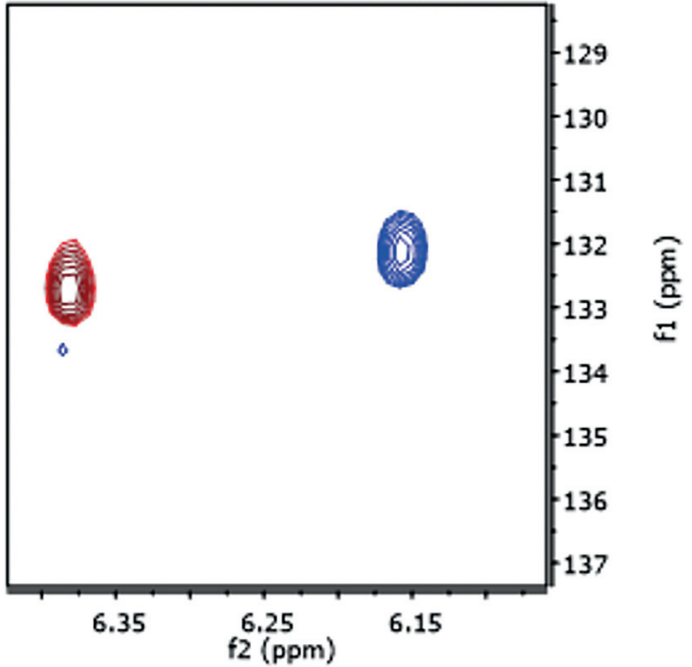

Figure $7{ }^{15} \mathrm{~N} \mathrm{HSQC}$ experiment for compound 1 to examine the ASIS effect on nitrogen nuclei. $\mathrm{C}_{6} \mathrm{D}_{6}$ (red) and $\mathrm{CDCl}_{3}$ (blue). $\Delta \delta(\mathrm{ASIS})=0.6$ $\mathrm{ppm}$, which corresponds to a deshielding effect due to the anisotropy of benzene.

With the aim of establishing the ASIS effect for tetramethyl $\beta$-lactams, we synthesized compound $7 .{ }^{19}$ In CD$\mathrm{Cl}_{3}$, the ${ }^{1} \mathrm{H}$ NMR spectrum of $\mathbf{7}$ showed singlet signals at $\delta=$ 1.11 and $1.22 \mathrm{ppm}$ for $\mathrm{CH}_{3}-5$ and $\mathrm{CH}_{3}-6$, respectively (Figure 8a). It is interesting to note that in $\mathrm{C}_{6} \mathrm{D}_{6}$, the chemical shifts of $\mathrm{CH}_{3}-5$ were located at low fields whereas those for $\mathrm{CH}_{3}-6$ were located at high fields (Figure 8b).

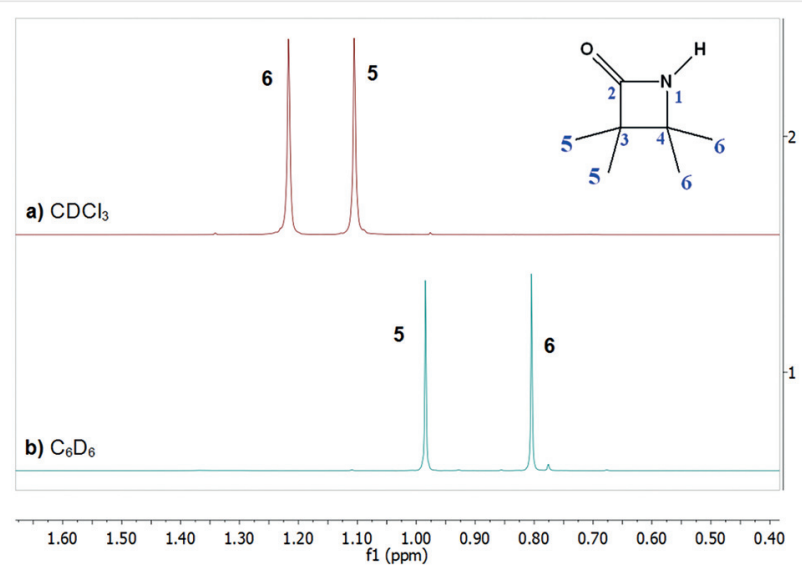

Figure $8{ }^{1} \mathrm{H}$ NMR (500 MHz) spectra of $\beta$-lactam 7 in (a) $\mathrm{CDCl}_{3}$ and (b) $\mathrm{C}_{6} \mathrm{D}_{6}$

HMBC spectra recorded in $\mathrm{CDCl}_{3}$ and $\mathrm{C}_{6} \mathrm{D}_{6}$ were used to assign protons $\mathrm{CH}_{3}-5$ and $\mathrm{CH}_{3}-6$ unambiguously. In $\mathrm{CDCl}_{3}$, the shift in the signal corresponding to protons $\mathrm{CH}_{3}-5$ to $1.11 \mathrm{ppm}$ allowed us to correctly assign the correlation with $\mathrm{C}-5, \mathrm{C}-3, \mathrm{C}-4$, and $\mathrm{C}(\mathrm{O})$ at $175.35 \mathrm{ppm}$, whereas proton $\mathrm{CH}_{3}-6$ at $1.22 \mathrm{ppm}$ correlated only with C-6, C-3, and C-4 (Figure 9). 


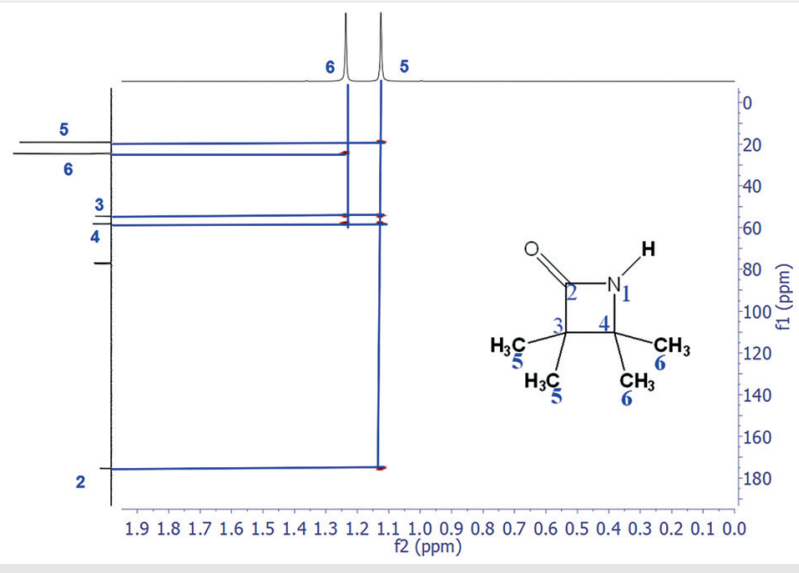

Figure $9 \mathrm{HMBC}(500 \mathrm{MHz})$ of $\beta$-lactam 7 in $\mathrm{CDCl}_{3}$

On the other hand, in the HMBC spectra recorded in benzene- $d_{6}$, the signal corresponding to the $\mathrm{CH}_{3}-5$ proton shifted by $0.98 \mathrm{ppm}$ again showed the same correlation with $\mathrm{C}-5, \mathrm{C}-3, \mathrm{C} 4$, and $\mathrm{C}(\mathrm{O})$ at $174.32 \mathrm{ppm}$, whereas proton $\mathrm{CH}_{3}-6$ at $0.86 \mathrm{ppm}$ correlated only with $\mathrm{C}-6, \mathrm{C}-3$, and $\mathrm{C}-4$ (Figure 10).

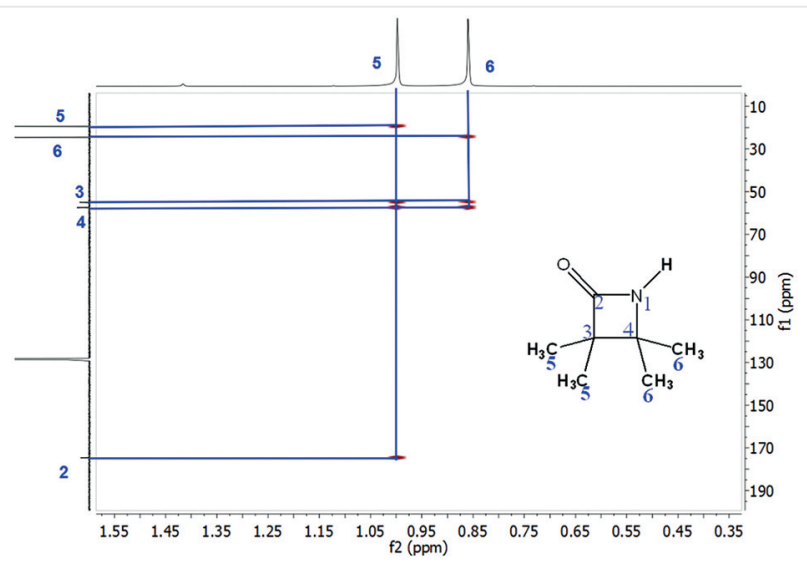

Figure $10 \mathrm{HMBC}(500 \mathrm{MHz})$ of $\beta$-lactam 7 in $\mathrm{C}_{6} \mathrm{D}_{6}$

Finally, a titration experiment with $5.0 \times 10^{-5}$ moles of $\beta$-lactam 7 in $350 \mu \mathrm{L}$ of $\mathrm{CDCl}_{3}$ was carried out. When $0.7 \mu \mathrm{L}$ aliquots of $\mathrm{C}_{6} \mathrm{D}_{6}$ were added, the signals for $\mathrm{CH}_{3}-5$ and $\mathrm{CH}_{3}$ 6 approached then overlapped one another (Figure 11). Surprisingly, however, at $1.4 \mu \mathrm{L}\left(2.26 \times 10^{-3} \mathrm{~mol}\right)$ of $\mathrm{C}_{6} \mathrm{D}_{6}$, a single signal at $\delta=1.1 \mathrm{ppm}$ corresponding to $\mathrm{CH}_{3}-5$ and $\mathrm{CH}_{3}-6$ was observed. At a higher concentration of $\mathrm{C}_{6} \mathrm{D}_{6}\left(3.39 \times 10^{-3}\right.$ mol; $2.1 \mu \mathrm{L}$ ), $\mathrm{CH}_{3}-5$ and $\mathrm{CH}_{3}-6$ could be differentiated once more, but at this point, their chemical shifts reversed, as in $100 \% C_{6} D_{6}$. Changing the solvent usually results in preferential movement of one signal more than the other, but after addition of $2.8 \mu \mathrm{L}\left(4.51 \times 10^{-3} \mathrm{~mol}\right)$ of $\mathrm{C}_{6} \mathrm{D}_{6}$, the signal corresponding to $\mathrm{CH}_{3}-6$ appeared to split into two signals.

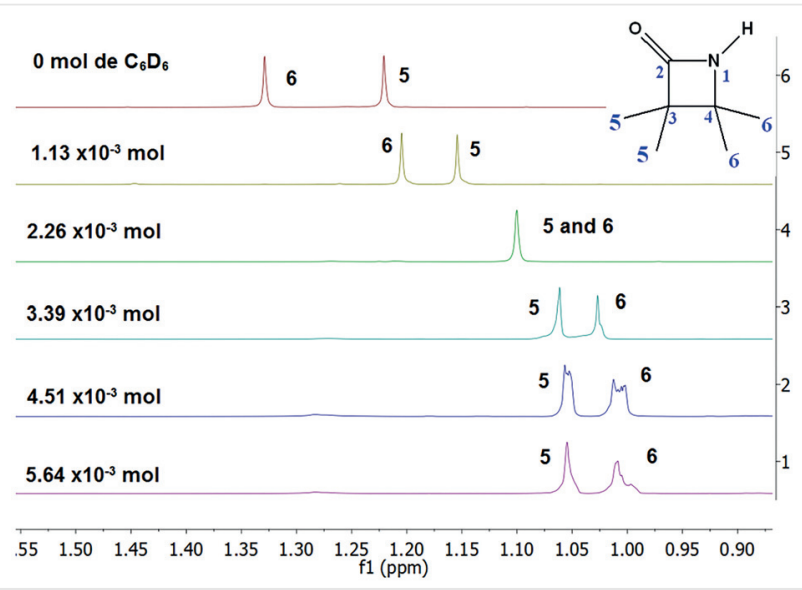

Figure $11{ }^{1} \mathrm{H}$ NMR $(500 \mathrm{MHz})$ of $\beta$-lactam 7 in $\mathrm{CDCl}_{3}$ with increasing concentrations of $\mathrm{C}_{6} \mathrm{D}_{6}$

A possible explanation of this is that $\mathrm{C}_{6} \mathrm{D}_{6}$ as a solvent allows us to differentiate $\mathrm{CH}_{3}-6-\alpha$ from $\mathrm{CH}_{3}-6-\beta$ (Figure 12).

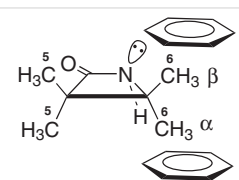

Figure 12 Possible interaction between $\beta$-lactam 7 in benzene- $d_{6}$ permitting differentiation of $\mathrm{CH}_{3}-6-\alpha$ and $\mathrm{CH}_{3}-6-\beta$

Crystals of 3,3,4,4-tetramethylazetidin-2-one (7) suitable for X-ray diffraction analysis were obtained by slow diffusion of a chloroform solution of the lactam at room temperature. Lactam 7 crystallized in an orthorhombic system with a cell volume of 751.95(2) $\AA^{3}$ and space group $\mathrm{P} 2{ }_{1} 22_{1} \cdot{ }^{20}$ The minimum repetitive unit consist of one molecule of the $\beta$-lactam (Figure 13a). A structural analysis revealed the formation of a four-membered planar ring consisting of atoms $\mathrm{C} 1, \mathrm{C} 2, \mathrm{C} 3$, and $\mathrm{N} 1$. The bond distances ranged between $1.3359(18)$ and $1.5910(18) \AA$, being shorter for C1-N1 and C3-N1, respectively. The four-membered ring is slightly bent, with a dihedral angle of $2.5^{\circ}$ between the $\mathrm{C} 2, \mathrm{C} 1, \mathrm{~N} 1$ plane and the $\mathrm{C} 2, \mathrm{C} 3, \mathrm{~N} 1$ plane. The structure
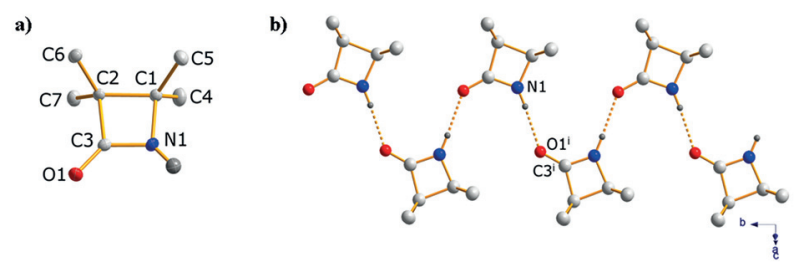

Figure 13 Solid-state structure of 3,3,4,4-tetramethylazetidin-2-one (7); (a) asymmetric unit and (b) 1D supramolecular tape formed through hydrogen bonding. Symmetry operators: (i) $2-x,-0.5+y, 1.5-z$. Some hydrogens atoms are omitted for clarity. Thermal ellipsoids are drawn at the $50 \%$ probability level. 
forming the $C_{1}^{1}(4)$ chain pattern is typical of many $\mathrm{N}-\mathrm{H} \cdots \mathrm{O}=\mathrm{C}$ hydrogen-bonded systems $(\mathrm{N}-\mathrm{H}, 0.86 \AA$; $\mathrm{H} \cdots \mathrm{O}$, $2.00 \AA ̊$; $N \cdots \mathrm{O}, 2.857 \AA$; $\angle N-\mathrm{H} \cdots \mathrm{O}, 175^{\circ}$ ) (Figure 13b).

Intermolecular interactions of 3,3,4,4-tetramethylazetidin-2-one (7) were analyzed by using a Hirshfeld surface, ${ }^{20}$ a powerful technique for understanding the nature of the intermolecular interactions within a crystalline structure. The surface was drawn from single-crystal X-ray structures in the CIF format by using Crystal Explorer software. ${ }^{21}$ The surface was mapped over the $d_{\text {norm }}$ function in the range 0.6-2.6 $\AA$; the red regions show contact points shorter than the sum of the van der Waals radii with negative $d_{\text {norm }}$ (complementary hollows). The blue regions are contact sites longer than the sum of the van der Waals radii with $d_{\text {norm }}$ negative equal to zero (bumps where the surfaces of two molecules touch each other). For compound 7, red areas on the surface mapped with $\mathrm{d}_{\text {norm }}$ function were located on the amide moieties due to the formation of hydrogen bonds (Figure 14a).

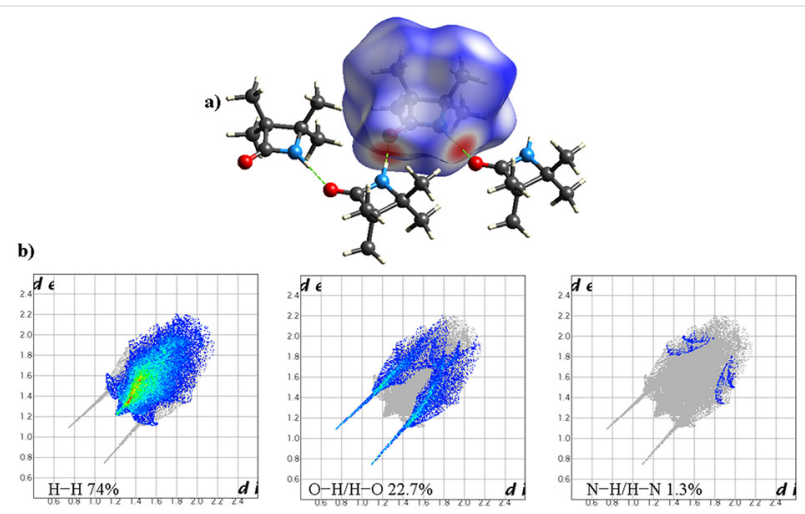

Figure 14 (a) Hirshfeld surface for 3,3,4,4-tetramethylazetidin-2-one (7) mapped with $d_{\text {norm. }}$ (b) Representative 2D fingerprints plots.

Decomposition of this surface to provide a molecular fingerprint (a directly accessible 2D plot that provides the full distribution of interactions) was performed by using $d_{\mathrm{i}}$ and $d_{\mathrm{e}}$, which are defined as the distances from the surface of the Hirshfeld surface to the nearest core within or outside the surface, respectively. In the 2D fingerprint plots of 7, $\mathrm{H}-\mathrm{H}$ interactions predominate, with a percentage of $74 \%$; these appear where $\mathrm{d}_{\mathrm{e}} \approx \mathrm{d}_{\mathrm{i}}$ near the van der Waals radius of the hydrogen atom (1.20 $\AA$ ). The percentage of $\mathrm{O}-\mathrm{H} / \mathrm{O}-\mathrm{H}$ contacts is $22.7 \%$, and these appear as a pair of long sharp spikes characteristic of a strong hydrogen bond (Figure 14b). The minimum contributions are attributed to $\mathrm{N}-\mathrm{H} / \mathrm{H}-\mathrm{N}$ and $\mathrm{C}-\mathrm{H} / \mathrm{H}-\mathrm{C}$ contacts.

In conclusion, we have demonstrated an ASIS effect in eight $\beta$-lactam derivatives by using deuterated chloroform and benzene solvents. The stacking adduct of the benzene ring with the lactam ring plays a determining role in chemical-shift changes. $N$-Methyl groups exhibited the best shielded effect in H-4 lactam protons, whereas in te- tramethylated $\beta$-lactams, the ASIS effect is lower than that in the other lactams synthesized. In $\beta$-lactams with anisotropic substituents, it was observed that protons $\mathrm{H}-3$ and $\mathrm{H}-4$ are already affected by the anisotropy of the substituent itself. Consequently, an intercalative interaction between the $\beta$-lactam and benzene- $d_{6}$ might overestimate these changes. From a theoretical point of view, we have demonstrated that at least one staking interaction between the $\beta$-lactam and the molecule of benzene is necessary to produce the changes in the chemical shifts. ${ }^{15} \mathrm{~N}$ HSQC results confirm the presence of a deshielded effect over the amide moiety while the protons of the ring are shielded.

\section{Funding Information}

Consejo Nacional de Ciencia y Tecnología (CB2015/256653).

\section{Acknowledgment}

We would like to thank CONACyT for financial support (Project No. CB2015/256653). L.C.-H., J.R.V.-C., and M.G.V.-R. are grateful to CONACyT for scholarships.

\section{Supporting Information}

Supporting information for this article is available online at https://doi.org/10.1055/s-0039-1691498.

\section{References and Notes}

(1) Williams, D. H.; Wilson, D. A. J. Chem. Soc. B 1966, 144.

(2) Rummens, F. H. A.; Krystynak, R. J. Am. Chem. Soc. 1972, 94, 6914.

(3) Hatton, J. V.; Richards, R. E. Mol. Phys. 1962, 5, 139.

(4) Bothner-By, A. A.; Glick, R. E. J. Chem. Phys. 1957, 26, 1651.

(5) Laszlo, P.; Schleyer, P. von. R. J. Am. Chem. Soc. 1964, 86, 1171.

(6) Schneider, W. G. J. Phys. Chem. 1962, 66, 2653.

(7) Schaefer, T.; Schneider, W. G. J. Chem. Phys. 1960, 32, 1218.

(8) Klinck, R. E.; Stonthers, J. B. Can. J. Chem. 1962, 40, 1071.

(9) Barfield, M.; Grant, D. M.; Ikenberry, D. J. Am. Chem. Soc. 1975, 97, 6956.

(10) Hatton, J. V.; Schneider, W. G. Can. J. Chem. 1962, 40, 1285.

(11) Laszio, P.; Engler, E. M. J. Am. Chem. Soc. 1971, 93, 1317.

(12) Kalyanam, N. J. Chem. Educ. 1983, 60, 635.

(13) Yukihiko, I.; Taku, M. Bull. Chem. Soc. Jpn. 1967, 40, 2030.

(14) Williams, D. H.; Bhacca, N. S. Tetrahedron 1965, 2021.

(15) Hernández-Vázquez, L. G.; Leyva, M. A.; Metta-Magaña, A. J.; Escalante, J. Helv. Chim. Acta 2012, 95, 2218.

(16) N-Alkylation of $\boldsymbol{\beta}$-Lactams; General Procedure

A $10 \mathrm{~mL}$ flask equipped with a magnetic stirrer was charged with the appropriate $\beta$-lactam $(1 \mathrm{mmol})$ in anhyd THF $(5 \mathrm{~mL})$. The solution was cooled to $-10{ }^{\circ} \mathrm{C}$ and treated with $\mathrm{Bu}_{4} \mathrm{NBr}(0.1$ equiv), the appropriate alkyl iodide or bromide ( 3 equiv), and freshly ground $\mathrm{KOH}$ pellets ( 1.6 equiv). After $2 \mathrm{~h}$, the temperature was allowed to rise to $-7{ }^{\circ} \mathrm{C}$ and the mixture was stirred overnight. The temperature was then increased to $0{ }^{\circ} \mathrm{C}$ and, when the reaction was nearly complete (TLC; 5 h), it was quenched with sat. aq $\mathrm{NH}_{4} \mathrm{Cl}$. The mixture was extracted with 
EtOAc and the extracts were purified by chromatography [silica gel, hexane-EtOAc (1:1)]. The spectral data for the lactams were consistent with those reported in the literature. ${ }^{16,22,23}$

1-Methylazetidin-2-one (2)

Yield: $23 \mathrm{mg}$ (28\%). FTIR (ATR): $1724.05(\mathrm{C}=0) \mathrm{cm}^{-1} .{ }^{1} \mathrm{H}$ NMR $\left(400 \mathrm{MHz}, \mathrm{CDCl}_{3}\right): 3.23\left(\mathrm{t},{ }^{3} \mathrm{~J}=4 \mathrm{~Hz}, 2 \mathrm{H}, \mathrm{CH}_{2} \mathrm{~N}\right), 2.95\left(\mathrm{t},{ }^{3} \mathrm{~J}=4 \mathrm{~Hz}\right.$, $\left.2 \mathrm{H}, \mathrm{CH}_{2} \mathrm{C}=0\right), 2.83\left(s, 3 \mathrm{H}, \mathrm{CH}_{3}\right) .{ }^{13} \mathrm{C}$ NMR $\left(100 \mathrm{MHz}, \mathrm{CDCl}_{3}\right)$ : 170.4, 43.3, 39.9, 31.3.

(17) Tsuzuki, S.; Honda, K.; Uchimaru, T.; Mikami, M.; Tanabe, K. J. Am. Chem. Soc. 2000, 122, 3746.

(18) Nishio, M. CrystEngComm 2004, 6, 130.

(19) 3,3,4,4-Tetramethylazetidin-2-one (7)

2,3-Dimethylbut-2-ene ( $16.8 \mathrm{mmol}, 2.0 \mathrm{~mL}, 1.5$ equiv) in a $100 \mathrm{~mL}$ round-bottom flask was treated with chlorosulfonyl isocyanate $(11.5 \mathrm{mmol}, 1.0 \mathrm{~mL})$ at $0-5{ }^{\circ} \mathrm{C}$ under $\mathrm{N}_{2}$. The mixture became solid and was then dissolved in $\mathrm{CHCl}_{3}(2.4 \mathrm{~mL})$ and treated with $2 \mathrm{M}$ aq $\mathrm{NaSO}_{3}$ (17.38 mL, $34.5 \mathrm{mmol}, 3$ equiv). The reaction flask was then fitted with a reflux condenser and a stirrer bar and placed in a Discover CEM microwave oven. The microwave oven was programmed by the open-vessel method to heat at $80^{\circ} \mathrm{C}$ at a microwave power of $50 \mathrm{~W}$. The mixture was heated for $5 \mathrm{~min}$ and then allowed to cool to below $50{ }^{\circ} \mathrm{C}$. After extraction with $\mathrm{CH}_{2} \mathrm{Cl}_{2}(4 \times 3 \mathrm{~mL})$, the two phases were separated and the organic phase was dried $\left(\mathrm{Na}_{2} \mathrm{SO}_{4}\right)$ and concentrated under reduced pressure. The resulting crude product was purified by column chromatography [silica gel, hexaneEtOAc (8:2 to 4:6)] to give white crystals; yield: $1.23 \mathrm{~g}(84 \%)$; mp $98-99^{\circ} \mathrm{C}$.

${ }^{1} \mathrm{H}$ NMR $\left(400 \mathrm{MHz}, \mathrm{CDCl}_{3}\right): \delta=1.22\left(\mathrm{~s}, 6 \mathrm{H}, \mathrm{CH}_{3}-\mathrm{C}-\mathrm{N}\right), 1.11(\mathrm{~s}, 6$ $\left.\mathrm{H}, \mathrm{CH}_{3}-\mathrm{C}-\mathrm{C}=\mathrm{O}\right) .{ }^{13} \mathrm{C} \mathrm{NMR}\left(100 \mathrm{MHz}, \mathrm{CDCl}_{3}\right): \delta=19.2,24.5,54.5$, 58.21, 175.4. FAB-MS: $m / z=128[\mathrm{M}+\mathrm{H}]^{+}$. HRMS (FAB): $m / z[\mathrm{M}+$ $\mathrm{H}]^{+}$calcd for $\mathrm{C}_{7} \mathrm{H}_{14} \mathrm{NO}$ : 128.1070 ; found: 128.1022 .

(20) CCDC 1487449 contains the supplementary crystallographic data for compound 7. The data can be obtained free of charge from The Cambridge Crystallographic Data Centre via www.ccdc.cam.ac.uk/getstructures.

(21) Wolf, S. K.; Grimwood, D. J.; McKinnon, J. J.; Turner, M. J.; Jayatilaka, D.; Spackman, M. A. Crystal Explorer, v. 3.1 2013.

(22) Hanai, K.; Maki, Y.; Kuwae, A. Spectrochim. Acta, Part A 1986, 42, 861.

(23) McKinnon, J. J.; Jayatilaka, D.; Spackman, M. A. Chem. Commun. 2007, 3814 